\title{
Enhanced Resistance to Fusarium graminearum in Transgenic Arabidopsis Plants Expressing a Modified Plant Thionin
}

\author{
Guixia Hao, † Matthew G. Bakker, and Hye-Seon Kim \\ Mycotoxin Prevention and Applied Microbiology Research Unit, NCAUR, U.S. Department of Agriculture-Agricultural Research Service, \\ Peoria, IL 61604 \\ Accepted for publication 5 February 2020.
}

\begin{abstract}
The fungal pathogen Fusarium graminearum causes Fusarium head blight (FHB) on wheat, barley, and other grains. FHB results in yield reductions and contaminates grain with trichothecene mycotoxins, which threaten food safety and food security. Innovative mechanisms for controlling FHB are urgently needed. We have previously shown that transgenic tobacco and citrus plants expressing a modified thionin (Mthionin) exhibited enhanced resistance toward several bacterial pathogens. The aim of this study was to investigate whether overexpression of Mthionin could be similarly efficacious against $F$. graminearum, and whether transgenic expression of Mthionin impacts the plant microbiome. Transgenic Arabidopsis plants expressing Mthionin were generated and confirmed. When challenged with $F$. graminearum, Mthionin-expressing plants showed less disease and fungal biomass in both leaves and inflorescences compared with control plants. When infiltrated into leaves, macroconidia of $F$. graminearum germinated at
\end{abstract}

ABSTRACT lower rates and produced less hyphal growth in Arabidopsis leaves expressing Mthionin. Moreover, marker genes related to defense signaling pathways were expressed at significantly higher levels after F. graminearum infection in Mthionin transgenic Arabidopsis plants. However, Mthionin expression did not appreciably alter the overall microbiome associated with transgenic plants grown under controlled conditions; across leaves and roots of Mthionin-expressing and control transgenic plants, only a few bacterial and fungal taxa differed, and differences between Mthionin transformants were of similar magnitude compared with control plants. In sum, our data indicate that Mthionin is a promising candidate to produce transgenic crops for reducing FHB severity and ultimately mycotoxin contamination.

Keywords: disease resistance, Fusarium graminearum, microbiome, modified plant thionin, phytohormone, transgenic plant
Plants are under attack continually by various pathogens and pests. To defend against pathogen invasion, plants produce a variety of antimicrobial proteins (AMPs) such as lipid transfer proteins, plant defensins, and thionins (Castro and Fontes 2005; Pelegrini and Franco 2005). Antimicrobial proteins and peptides have been isolated and synthesized for disease control. Typically, AMPs are short peptides with fewer than 50 amino acid residues that have broad-spectrum antimicrobial activities against various pathogens (Montesinos 2007). Most AMPs are cationic and able to bind to the surface of microbes, allowing them to directly interact with and disrupt the membrane of the pathogen by forming carpet-like clusters and increasing membrane permeabilization (Jung and Kang 2014). In order to increase the activity against pathogens, chimerical constructions, such as a cecropin-melittin chimeric gene, and modified sequences have been designed to increase target specificity and reduce toxicity to mammalian and animal cells (Montesinos 2007). Expression of AMPs in transgenic plant species

${ }^{\dagger}$ Corresponding author: Guixia Hao; E-mail: guixia.hao@usda.gov

Current address for M. G. Bakker: Department of Microbiology, University of Manitoba, Winnipeg, MB R3T 2N2, Canada.

Funding: Support was provided by the U.S. Department of Agriculture-Agricultural Research Service National Program for Food Safety.

Mention of trade names or commercial products in this publication is solely for the purpose of providing specific information and does not imply recommendation or endorsement by the U.S. Department of Agriculture. USDA is an equal opportunity provider and employer.

*The $e$-Xtra logo stands for "electronic extra" and indicates that seven supplementary figures and three supplementary tables are published online.

The author(s) declare no conflict of interest.

(C) 2020 The American Phytopathological Society has provided different degrees of protection against some fungal and bacterial pathogens (Montesinos 2007). For instance, the expression of naturally occurring peptides and their synthetic analogs conferred resistance to pathogens in transgenic plants including Arabidopsis, tobacco, Chinese cabbage, rice, cotton, tomato, potato, pear, banana, and hybrid poplar (Montesinos 2007). In addition, overexpression of some AMPs leads to disease resistance against a broad range of bacterial and fungal pathogens (Ali et al. 2018). For example, transgenic tobacco plants expressing Rs-AFP2 showed enhanced resistance toward the phytopathogenic fungus Alternaria longipes (Lacerda et al. 2014). Moreover, transgenic apple, tomato, and rice plants expressing the Rs-AFP2 showed resistance to several phytopathogenic fungi, including Fusarium culmorum, F. solani, F. oxysporum, Phytophthora infestans, Rhizoctonia solani, and Magnaporthe oryzae (Lacerda et al. 2014).

Thionins have a broad range of antibacterial, antifungal, and cytotoxic activities (Guzmán-Rodríguez et al. 2015). The expression of many thionins is highly induced during incompatible interactions; whereas in compatible interactions, lower thionin expression is detected. For example, the induction of Asthi2.4 expression was higher in a resistant Arabidopsis ecotype compared with a susceptible ecotype (Epple et al. 1995). Purified thionins from barley and wheat seed increase permeabilization in fungal hyphae within minutes of exposure (Thevissen et al. 1996). Furthermore, overexpression of plant thionins in transgenic plants exhibits enhanced resistance against a broad range of bacterial and fungal diseases (Chan et al. 2005; Epple et al. 1997; Iwai et al. 2002; Muramoto et al. 2012).

The mature thionins from plants such as wheat and barley contain 44 to 47 amino acids, including six to eight conserved cysteine residues (Pelegrini and Franco 2005). Thionins induce the opening of pores on cell membranes, disrupt potassium and calcium ion balance, and result in leakage of proteins, nucleotides, and other cell 
components from cells (Pelegrini and Franco 2005). $\alpha$-Hordothionin from barley also causes increased potassium efflux and alkalization of the medium, leading to rupture of the membrane lipid bilayers (Oard 2011). The pyrularia thionin is toxic to insects and mammals when injected into body fluids, but nontoxic when taken orally (Vernon 1992). To reduce off-target toxicity and to increase efficacy, a modified thionin (Mthionin) was previously designed and synthesized, which differs from the native citrus thionins by modified amino acid compositions and the addition of five extra amino acids at the C-terminus (Hao et al. 2016a). We demonstrated that transgenic citrus expressing this Mthionin showed markedly enhanced disease resistance toward Pseudomonas tabaci, Xanthomonas citri, and 'Candidatus Liberibacter asiaticus' (Hao et al. 2016a; Stover et al. 2017).

In relation to Fusarium head blight, thionin accumulation has been shown to increase significantly in infected cell walls of the wheat lemma, ovary, and rachis after F. culmorum inoculation, compared with levels in healthy tissues (Kang and Buchenauer 2003). This study suggests that the accumulation of thionins in infected wheat cell walls may be associated with defense responses against $F$. culmorum or $F$. graminearum (Kang and Buchenauer 2003). The secreted antifungal thionin Asthi2.4 has been shown to suppress the toxicity of a fungal fruit body lectin from F. graminearum and overexpression of the Asthi2.4 in transgenic Arabidopsis increases resistance toward $F$. graminearum (Asano et al. 2013). The pathosystem of Arabidopsis and F. graminearum resembles wheat-Fusarium interactions (Urban et al. 2002), though mycotoxins play a minor role during Arabidopsis infection (Cuzick et al. 2008). Due to the long cycle of wheat growth and the difficulty of achieving wheat transformation, Arabidopsis transformation provides an advantage for investigation of the efficacy with which AMPs inhibit $F$. graminearum.

In this study, we introduced the Mthionin into Arabidopsis and generated transgenic plants. We assessed whether overexpression of the Mthionin in transgenic Arabidopsis can increase resistance to $F$. graminearum. We further determined the effect of Mthionin expression on plant salicylic acid (SA), jasmonic acid and the ethylene (JA/ET) marker genes after $F$. graminearum infection. To investigate whether the expression of Mthionin affects the microbiome of the plant, we profiled bacterial and fungal communities associated with transgenic Arabidopsis expressing Mthionin or GUS.

\section{MATERIALS AND METHODS}

Generation of transgenic Arabidopsis. The pBinARS/plus vector carrying Mthionin driven by a double 35S (D35S) promoter (Hao et al. 2016a), was used for Arabidopsis transformation. The kanamycin resistance gene (nptII) served as a selection marker for transformants. Arabidopsis (Arabidopsis thaliana) wild-type (Columbia ecotype Col-0) plants were transformed using the floral dip method. Similarly, the pBinARS/plus vector containing GUS was used to generate transgenic Arabidopsis plants as controls. Transgenic plants were selected on MS media containing kanamycin at $50 \mathrm{mg} /$ liter. The seedlings were grown in a growth chamber at $22^{\circ} \mathrm{C}$ in a 16/8 h light/dark cycle. Plant genomic DNA was isolated with the Qiagen plant kit (Qiagen, Valencia, CA). The primers D35S-F and Nos-R were used for screening transformants by PCR as described (Supplementary Table S1). To obtain homozygotes for further experiments, T2 seeds were sown on a medium containing kanamycin $(50 \mathrm{mg} / \mathrm{liter})$ for a progeny test; the transgenic lines for which T2 seedlings showed no segregation were considered as homozygotes. Homozygous T3 lines were used for estimating Mthionin copy number by quantitative PCR (qPCR). The Arabidopsis gene 4-hydroxyphenypyruvate dioxygenase (4HPPD), which is a single copy gene, was used as the endogenous reference gene (Garcia et al. 1999). Primer efficiency for Mthionin and $4 H P P D$ was determined using a standard curve consisting of a dilution series for each primer pair. The qPCR amplification efficiency was calculated according to the following equation: efficiency $=10^{(-1 / \text { slope })}-1$. The ratio of the copy number of Mthionin was calculated using the following equation: ratio $=1+$ efficiency $\left(\mathrm{Ct}_{\text {Mthionin }}\right) / 1+\operatorname{efficiency}\left(\mathrm{Ct}_{4 \mathrm{HPPD}}\right)$. The $\mathrm{qPCR}$ reactions were set up in triplicate and repeated three times. Data were shown as means \pm SD of three replicates.

RNA isolation and reverse transcription qPCR (RTqPCR). RNA was extracted from leaves of T0 transgenic Arabidopsis plant using Trizol reagent (Sigma-Aldrich, St. Louis, MO) as described elsewhere (Hao et al. 2016b). Total RNA was quantified with a spectrophotometer (Nanodrop; Thermo Fisher Scientific, Waltham, MA) and treated with RQ1 RNase-free DNase (Promega Corp., Madison, WI). The first-strand cDNA was synthesized using DNase-treated RNA $(\sim 1.5 \mu \mathrm{g}), 0.5 \mu \mathrm{g}$ of oligo (dT) primer, and $1 \mu \mathrm{l}$ of SuperScript III reverse transcription (Invitrogen, Carlsbad, CA) in a $20 \mu \mathrm{l}$ reaction. The absence of genomic DNA contamination was verified. RT-qPCR was performed using primers Mthionin-RT-5', located in the modified gene, and Mthionin-RT-3', located in the Nos region (Supplementary Table S1). The Arabidopsis gene elongation factor 1-alpha $(E F l \alpha)$ was used to normalize the values as an internal control. Gene expression level was calculated with the $2^{-\Delta \Delta C t}$ method, relative to the transgenic plant having the lowest expression level, which was set as 1 . The qPCR reactions were set up in triplicate and repeated twice with similar results.

Virulence assays. F. graminearum strain $\mathrm{PH}-1$ was used for virulence assays. Conidial inoculum was prepared in mung bean liquid medium as described (Hao et al. 2019). Briefly, two plugs from a V8 plate were grown in mung bean liquid medium with shaking at $28^{\circ} \mathrm{C}$ for 4 days. The culture was filtered through a $40 \mu \mathrm{m}$ cell strainer (Biologix, Jinan, Shandong, China) and centrifuged for $10 \mathrm{~min}$ at $3,000 \times g$, and conidia were resuspended in water, and the concentration was adjusted to $5 \times 10^{5}$ conidia $/ \mathrm{ml}$.

A detached leaf assay (Chen et al. 2006; Makandar et al. 2006) was used, with some modifications. Briefly, leaves from homozygous transgenic Arabidopsis (T3) and control plants were wounded with a needle. In total, 16 leaves from four plants of each genotype (GUS and Mthionin plants) were infiltrated. Four leaves were infiltrated with water as mock controls, while 12 leaves were infiltrated with $F$. graminearum. Leaves were pricked on each side of the midvein with a needle and infiltrated from the abaxial leaf surface with a $1 \mathrm{ml}$ needleless syringe. The infiltrated leaves were maintained on $1 \%$ agar plates with high humidity. The plates were inoculated under dark. The disease progress was monitored every day and imaged at 4 days, at which time the leaves were collected for biomass evaluation. DNA was isolated from infiltrated leaves. Relative biomass of $F$. graminearum in the infected tissue was quantified by qPCR. The Ct value for the F. graminearum gene TRI6 was calculated relative to the corresponding $\mathrm{Ct}$ values for the Arabidopsis EFl $\alpha$ gene using the $2^{-\Delta \Delta \mathrm{Ct}}$ method (Livak and Schmittgen 2001). Three biological replicates were used for qPCR, with two technical replicates each. Means from three replicates were compared using one-way analysis of variance (ANOVA) and Tukey's honestly significant difference (HSD) post hoc test.

For inoculation of florets, young plants with open flowers and a few siliques were sprayed with $5 \times 10^{5} \mathrm{~F}$. graminearum conidia $/ \mathrm{ml}$ in $0.02 \%$ Tween 20 . Twelve to sixteen T3 homozygous transgenic plants from each transgenic line were inoculated. Four plants from each genotype were sprayed with $0.02 \%$ Tween 20 as controls. To create the high humidity conditions that promote successful infection, the inoculated plants were covered by a transparent plastic dome for 4 days. After this, the humidity was maintained at $80 \%$. Disease was assessed at 8 days using a modified FusariumArabidopsis disease (FAD) value (Nalam et al. 2015). Briefly, the rating scale was as follows: 0 , healthy flower or silique with no disease; level 1, flower (F) or new silique (NS) coved with aerial mycelium; level 3, flower or silique dried with disease; and level 5, 
dead branches due to disease progressing into the stem. FAD $=\mathrm{F}$ score + NS score. The FAD data were obtained for each plant by averaging scored flowers and siliques, because each genotype had varying numbers of pots with varying numbers of plants within a pot. Levene's homogeneity of variance test was conducted to determine whether FAD data needed a transformation before analysis of variance could be conducted. A mixed model single factor ANOVA was performed to compare FAD between genotypes. If a significant genotype effect was found, differences of least squares means with a Tukey adjustment were used to examine pairwise differences in FAD between genotypes. To investigate fungal growth, genomic DNA was isolated from infected florets and siliques. Relative biomass of $F$. graminearum in the infected tissue was quantified by qPCR, as described above. Three biological replicates were analyzed, with two technical replicates each. Means from three replicates were compared using one-way ANOVA and Tukey's HSD post hoc test.

Macroscopic examination of infection. A strain of $F$. graminearum expressing green fluorescent protein, kindly provided by R. Proctor, USDA-ARS, Peoria, IL, was used for study of fungal hyphal growth and spore germination in transgenic plant expressing Mthionin and GUS. Leaves from intact transgenic plants were infiltrated as described above. In total, eight leaves from three plants of each genotype were infiltrated and examined. Infiltrated leaves were examined under a microscope at 1 and 2 days after infiltration. The fields of view were close to infiltration holes but away from areas pressed with syringe. Conidial germination rates were averaged across at least 10 different fields of view to permit counting of approximately 100 spores. Photographs were taken under ultraviolet light with a fluorescence microscope and Axio Imager A1 software. The length of geminated spores was calculated from at least 10 images (20 to 40 spores) using Image J software. The experiments were repeated three times with similar results. One-way ANOVA and Tukey's HSD post hoc test were performed for statistical analysis.

Analysis of defense response genes. In addition to direct toxicity on fungal spore germination and hyphal growth, we investigated whether Mthionin expression influenced plant defense response signaling. Transgenic plants expressing GUS or Mthionin (A24 and A52) were used for gene expression analysis. The seeds of homozygous T3 (third generation) transgenic plants were germinated on MS medium containing kanamycin. After 10 days, eight plants from each transgenic line were transferred to potting soil. Three- to four-week-old plants were used for inoculation. Three leaves from four plants of each genotype were infiltrated with $2 \times$ $10^{5} \mathrm{~F}$. graminearum conidia/ml. Mock infiltration with water served as controls in parallel. Leaf samples were collected at 24 and $48 \mathrm{~h}$ postinoculation (hpi). Leaf samples from each treatment were pooled for RNA isolation and cDNA synthesis, as described above.

Defense response genes PRl (At2g14610), PR4 (At3g04720), and $P D F 1.2$ (At5g44420) were selected. $P R 1$ is a key marker gene during salicylate signaling, $P D F 1.2$ and $P R 4$ act as markers during jasmonate/ethylene signaling. The Arabidopsis gene EFl $\alpha$ was used to normalize the values as an internal control. Primers were designed and listed (Supplementary Table S1). qPCR was performed as above, and gene expression level was calculated with the $2^{-\Delta \Delta \mathrm{Ct}}$ method. Three-way ANOVA was used to compare means values between genotype (GUS, A24, and A52) $\times$ treatments (water and $F$. graminearum) at each time points (24 and 48 hpi). Letters indicate significantly different using the SLICE option in SAS $(P<$ 0.0001 ) based on differences of least square means at $P \leq 0.05$.

Microbiome profiling. We investigated the impacts of Mthionin expression on microbiomes associated with Arabidopsis, using transgenic plants expressing GUS or Mthionin (A24 or A52). The seeds of homozygous T3 (third generation transgenic) plants were germinated on MS medium containing kanamycin. After 10 days, five plants from each transgenic line were transferred to potting soil and inoculated with a diverse microbiota by irrigation with a suspension of field soil (Peoria, IL). The seedlings were grown in a growth chamber at $22^{\circ} \mathrm{C}$ in a $16 / 8 \mathrm{~h}$ light/dark cycle. At the onset of inflorescence formation, leaves and roots were harvested for DNA extraction from five transgenic plants of each transgenic line (GUS, Mthionin A24, or Mthionin A52). Leaves were clipped individually, wiped briefly with a tissue moistened with $70 \%$ ethanol, and frozen. Roots were washed with sterile tap water, dipped in $70 \%$ ethanol, rinsed again in sterile water, and frozen. Tissue was lyophilized and then pulverized by bead-beating, using a single 3-mm tungsten-carbide bead in a 2-ml XXTuff Microvial (BioSpec Products) and a Precellys 24 homogenizer (Bertin Technologies) set to 4,200 rpm for $30 \mathrm{~s}$ DNA was extracted from pulverized tissue using the PureLink Plant kit (Thermo Fisher Scientific), according to the manufacturer's directions.

Microbiome profiling was accomplished via amplicon sequencing, using primers $515 \mathrm{~F}$ and $806 \mathrm{R}$ (Caporaso et al. 2011) to amplify the $\mathrm{v} 4$ region of bacterial $16 \mathrm{~S}$ rRNA genes, and primers internal transcribed spacer (ITS)3_KYO2 and ITS4_KYO3 (Toju et al. 2012) to amplify the second internal transcribed spacer (ITS2) region of fungal rRNA genes. Primers were modified with 5' overhangs for compatibility with the MiSeq workflow and to create a frameshifted mixture of oligos to provide signal diversity when sequencing through the primer regions.

Each PCR reaction mix consisted of $0.5 \mathrm{U}$ of Phusion HighFidelity DNA polymerase with associated Phusion Green HF reaction buffer (Thermo Fisher), dNTPs at $200 \mu \mathrm{M}$ final concentration, forward and reverse primers at $0.5 \mu \mathrm{M}$ each, peptide nucleic acid blockers at $1 \mu \mathrm{M}$ (bacterial 16S rRNA gene samples only, to prevent amplification of plastid and mitochondrial templates; PNA Bio Inc.), $1 \mu \mathrm{l}$ of template DNA, and nuclease free water to a total volume of $25 \mu \mathrm{l}$ per reaction. Thermocycling for bacterial 16S rRNA amplification consisted of $98^{\circ} \mathrm{C}$ for $60 \mathrm{~s}, 25$ cycles $\left(98^{\circ} \mathrm{C}\right.$ for $10 \mathrm{~s}, 75^{\circ} \mathrm{C}$ for $10 \mathrm{~s}, 57^{\circ} \mathrm{C}$ for $20 \mathrm{~s}$, and $72^{\circ} \mathrm{C}$ for 15 $\mathrm{s}$ ), and final extension at $72^{\circ} \mathrm{C}$ for $5 \mathrm{~min}$. Thermocycling for fungal ITS amplification consisted of $98^{\circ} \mathrm{C}$ for $60 \mathrm{~s}, 25$ cycles $\left(98^{\circ} \mathrm{C}\right.$ for $10 \mathrm{~s}, 57^{\circ} \mathrm{C}$ for $20 \mathrm{~s}$, and $72^{\circ} \mathrm{C}$ for $15 \mathrm{~s}$ ), and final extension at $72^{\circ} \mathrm{C}$ for $5 \mathrm{~min}$. PCR products were cleaned using the SequalPrep Normalization Plate Kit (Thermo Fisher). An eight cycle second round PCR was used to add sample-specific barcode indices, using the Nextera XT Index Kit (Illumina). The manufacturer's protocol was followed, except that we substituted Phusion High-Fidelity DNA polymerase for the suggested polymerase.

Sequencing libraries also included negative control samples (i.e., DNA extractions performed without any plant tissue, and PCRs run without any template DNA), and mock community control samples of known composition. The mock bacterial community was product MSA-1003 from the American Type Culture Collection, while the mock fungal communities were from Bakker (2018).

Indexed amplicons were cleaned and normalized with the SequalPrep kit ahead of sample pooling. Library quality and concentration were assessed with the TapeStation instrument (Agilent) and with the Library Quantification Kit for Illumina Platforms (Kapa Biosystems). Sequencing was performed with a MiSeq instrument (Illumina), using a version 2 (500 cycle) sequencing kit for bacterial 16S rRNA amplicons, and a version 3 (600 cycle) sequencing kit for fungal ITS2 amplicons. Raw sequence data are available in the NCBI Sequence Read Archive (BioProject PRJNA520912).

Amplicon sequences were processed with the DADA2 pipeline (Callahan et al. 2016a) in R v.3.5 (R Core Team 2018). A complete record of commands issued during amplicon sequence processing is provided. Briefly, reads containing Ns were filtered out, and primer sequences were located and trimmed using the tool Cutadapt (Martin 2011). Reads were trimmed (15 bases from 3' end for R1, 40 bases from $3^{\prime}$ end for R2) and filtered to permit a maximum of two expected errors (Edgar and Flyvbjerg 2015). True sequence variants were inferred from the observed sequences with the 
DADA2 algorithm (Callahan et al. 2016b). Forward and reverse reads were merged, permitting one mismatch in the overlapping region. Chimeras were detected and removed using the DADA2 method. The ITS dataset was processed through ITSx v.1.1.1 (Bengtsson-Palme et al. 2013) to trim off conserved regions flanking ITS2, and to identify reads of likely nonfungal origin, which were culled. Sequence variants were assigned to taxonomic bins using a naïve Bayesian classifier (Wang et al. 2007), with the Silva reference alignment v. 132 (Quast et al. 2013) for the bacterial dataset and the UNITE database v. 7.2 (Kõljalg et al. 2013) for the fungal dataset. Reads were culled from the bacterial dataset if they could not be classified below the rank of domain, or were classified as chloroplast or mitochondria, and from the fungal dataset if they were classified as nonfungal in origin (e.g., Rhizaria). For assessment of phylogenetic diversity and distance measures, a phylogenetic tree was constructed (bacterial dataset only, due to the impossibility of aligning fungal ITS2 sequences) using the package phangorn (Schliep 2011), with a neighbor-joining tree as the starting point for a maximum likelihood tree (generalized timereversible with Gamma rate variation). Further manipulations, visualization, and analyses used the package phyloseq (McMurdie and Holmes 2013).

In processing taxon abundance tables from amplicon sequencing (one for bacteria, one for fungi), observations from the negative controls were evaluated manually to determine whether component taxa likely represented reagent contamination or sample cross contamination. Mock community controls were processed along with the biological samples. Differential abundance of taxa among Arabidopsis transformants was tested using the DESeq2 package for R (Love et al. 2014), with taxon counts modeled on tissue + genotype (bacterial dataset) or on genotype alone (fungal dataset). Processed taxon abundance tables are provided as Supplementary Tables.

\section{RESULTS}

Generation of transgenic Arabidopsis carrying Mthionin. The binary vector $\mathrm{pBinARS/plus} \mathrm{carrying} \mathrm{the} \mathrm{Mthionin} \mathrm{gene} \mathrm{driven} \mathrm{by}$ a double $35 \mathrm{~S}$ promoter was used for Arabidopsis transformation (Supplementary Fig. S1). A total of 80 putative transgenic Arabidopsis plants (T0 generation) were generated on kanamycincontaining selection medium. PCR amplification confirmed 64 transformants to be carrying the Mthionin gene. The PCR results of representative independent transgenic plants carrying the Mthionin gene are shown in Supplementary Figure S1, including the positive and negative control samples. The T2 seeds collected from the T1 transgenic plants were examined on kanamycin-containing selection medium. The transgenic lines displaying no segregation were considered as homozygous plants. Quantitative real-time PCR technique was used to determine the copy number of Mthionin in T3 homozygous transgenic Arabidopsis plants. For the endogenous reference control, we utilized the Arabidopsis gene 4-hydroxyphenypyruvate dioxygenase (4HPPD). The amplification efficiency of the target gene Mthionin and the Arabidopsis $4 H P P D$ was 96.8 and $101.9 \%$, respectively. Using the ratio formula calculation, we estimated one Mthionin insertion present in the selected Arabidopsis transgenic lines (Supplementary Table S2).

Mthionin expression in transgenic Arabidopsis. Mthionin expression in eight selected transgenic plants was determined by reverse transcription quantitative PCR (RT-qPCR). The relative RNA abundance showed that Mthionin transgenic plants, Mthionin A24 and A52, displayed higher expression levels, whereas A5 exhibited the lowest expression level (Fig. 1). No abnormal growth or phenotype was observed among transgenic plants. Compared with wild type and GUS transgenic Arabidopsis plants, Mthionin transgenic plants displayed similarity in the leaf number and size, flowering time, and plant height (Supplementary Table S3). These results indicate that transgenic expression of Mthionin in Arabidopsis has no significant effect on plant morphology.

Mthionin-enhanced resistance toward $F$. graminearum. F. graminearum can cause water-soaked spots, chlorosis, and lesions when infiltrated into Arabidopsis leaves. Detached leaf assays were performed to screen plants for resistance toward F. graminearum. The majority of transgenic plants displayed less disease symptoms compared with the transgenic plants expressing GUS and wild type controls. Four days after infiltration, watersoaking and lesions were observed in the infiltrated area of GUS transgenic plant and wild type controls (Fig. 2A). In contrast, the transgenic plants Mthionin A24 and A52 exhibited few watersoaking and lesion symptoms (Fig. 2A). Fungal biomass was determined by qPCR. Our results showed that fungal biomass reduced significantly in Mthionin transgenic leaves compared with GUS transgenic leaves (Fig. 2B).

To evaluate if Mthionin expression increases floral disease resistance in transgenic Arabidopsis plants, we introduced F. graminearum by spray inoculation. Plants containing open flowers were sprayed with a concentration of $5 \times 10^{5}$ conidia $/ \mathrm{ml}$ in $0.02 \%$ Tween 20 . GUS and Mthionin transgenic plants sprayed with $0.02 \%$ Tween 20 solution did not show any symptoms. Compared with GUS control plants, which developed severe symptoms including dry flowers, dry mycelium covered siliques, and dead branches, the transgenic plants expressing Mthionin showed reduced symptoms; mycelium was evident on some siliques, but many flowers did not show symptoms (Fig. 3A). The mean FAD value was significantly higher for GUS plants than for Mthionin plants (Fig. 3B). Furthermore, F. graminearum biomass in floral tissues was significantly reduced in transgenic plant expressing Mthionin (A24 and A52) compared with GUS transgenic plants (Fig. 3C). Markedly, there was no successful formation of siliques in the first experiment and only a few health siliques formed in the second and third experiment in GUS transgenic plants, whereas many healthy siliques formed in Mthionin transgenic plants in all experiments (data not shown). Taken together, these data indicate that transgenic Arabidopsis plants expressing Mthionin show enhanced resistance toward $F$. graminearum.

Mthionin inhibition of $F$. graminearum spore germination and growth in planta. To determine the potential mechanisms by which Mthionin may reduce infection following F. graminearum inoculation, leaves expressing Mthionin or GUS were infiltrated with an $F$. graminearum strain expressing a green fluorescent protein. Fluorescence microscopy demonstrated that the conidia of $F$. graminearum effectively germinated $(95 \%)$ on leaves of Arabidopsis expressing GUS and developed a dense

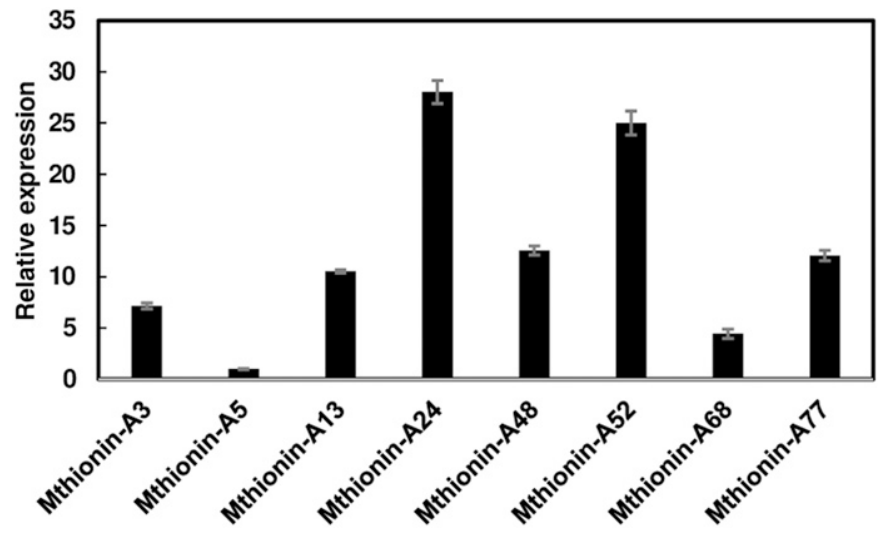

Fig. 1. Mthionin transgene expression in transgenic Arabidopsis plants (T0 generation). The expression of the Mthionin was normalized to the expression of the Arabidopsis elongation factor 1-alpha $(E F 1 \alpha)$. The relative gene expression is calculated from the $2^{-\Delta \Delta C}$ values of a sample versus Arabidopsis Mthionin A5, which had the lowest $2^{-\Delta C}$ among the tested samples. The experiments were set up in triplicate, and repeated twice. 
network of hyphae at $24 \mathrm{~h}$ postinoculation (hpi). In contrast, on Arabidopsis leaves expressing Mthionin, the majority of $F$. graminearum conidia were restricted to the infiltration area without germination (Fig. 4A). The germination rate reached about $10 \%$ in A24 transgenic plants and 25\% in A52 transgenic plants. Statistical analysis confirmed a significant germination reduction in Mthionin transgenic plants compared with GUS controls (Fig. 4B). Moreover, the conidia of $F$. graminearum on the GUS transgenic leaves often germinated at more than one site with normal long germ tube growth, septation and hyphal branching, and the hyphal growth was rapid and dense. In contrast, fewer conidia germinated normally on Mthionin-expressing leaves and the majority of them displayed rarely branched, short, bulbous and slightly curved abnormal germ tubes, and some hyphae exhibited enlarged vacuoles (Fig. 5A). Additionally, total hyphal length was significantly reduced in transgenic plants A24 and A52 compared with GUS plants (Fig. 5B). Taken together, these observations indicate that Mthionin may inhibit $F$. graminearum spore germination and hyphal growth.

Defense responses triggered by $F$. graminearum in transgenic Arabidopsis. Studies have shown that SA is critical for defense responses against $F$. graminearum, whereas the role of JA/ET pathway is inconclusive during Fusarium and Arabidopsis interactions (Brewer and Hammond-Kosack 2015). Therefore, we examined whether the increased resistance to $F$. graminearum in transgenic Arabidopsis plants expressing Mthionin is associated with phytohormone defense signaling. Two defense marker genes, $P R 1$ and $P R 4$, were reduced or unchanged at 24 hpi in Mthionin transgenic plants infiltrated with $F$. graminearum compared with GUS transgenic plants or Mthionin plants infiltrated with water; whereas $P D F 1.2$ was upregulated significantly in Mthionin transgenic plants infiltrated with $F$. graminearum compared with control plants infiltrated with water. However, PDF1.2 displayed the highest expression in water infiltrated GUS plants (Fig. 6A to C). Furthermore, all three marker genes exhibited a significant induction at $48 \mathrm{hpi}$ in $F$. graminearum infiltrated Mthionin plants compared with a water infiltrated control or with GUS transgenic plants infiltrated with either $F$. graminearum or water. Compared with the water infiltrated control, the expression of these three genes was significantly up-regulated in GUS and Mthionin plants following $F$. graminearum inoculation (Fig. 6D to F). Our results indicate that plant defense responses are enhanced in Mthionin transgenic plants after $F$. graminearum infection.

Impacts of Mthionin expression on the microbiome. Since transgenic plants expressing Mthionin have displayed a broad-spectrum resistance against bacteria in citrus roots and fungal pathogens in tobacco and Arabidopsis leaves, we characterized and compared the microbial populations associated with leaves and roots of transgenic Arabidopsis expressing either Mthionin or
A
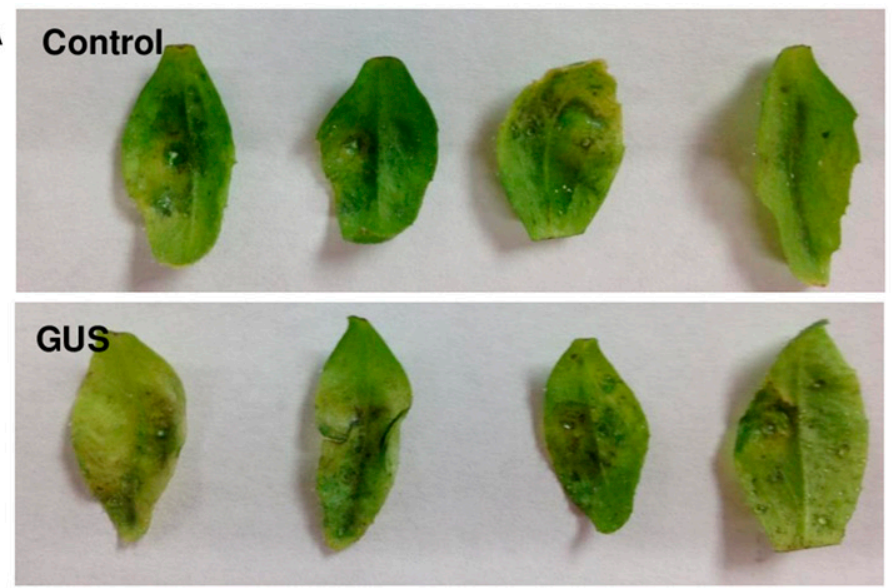

A24
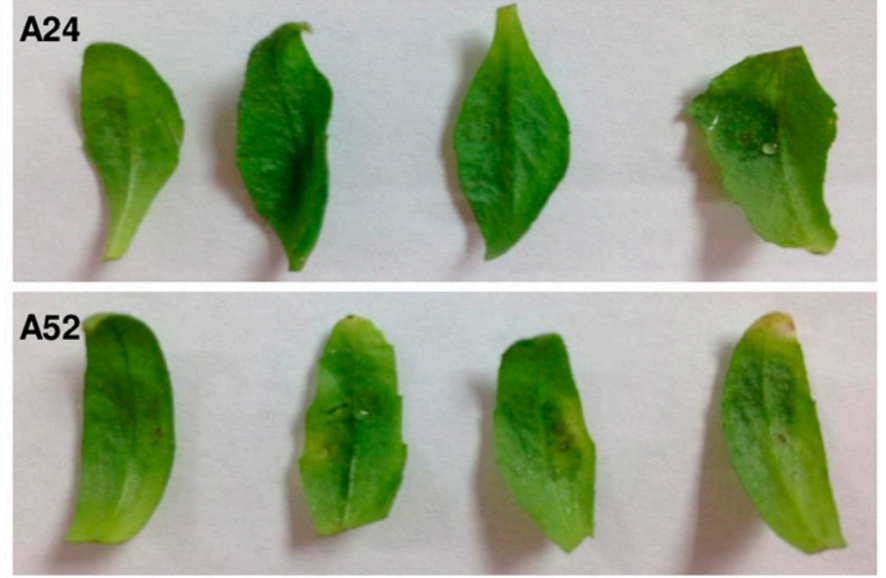

B

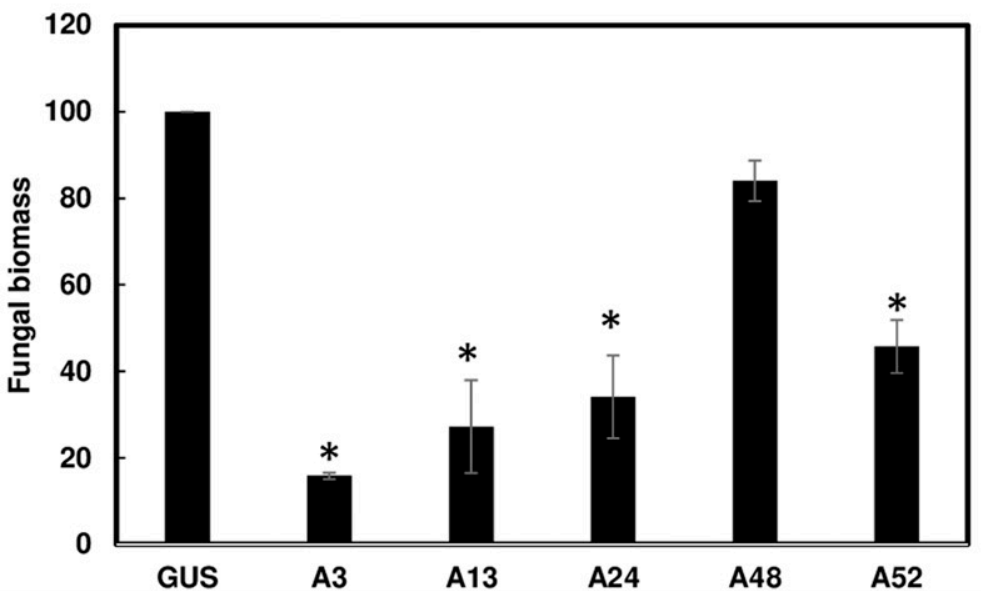

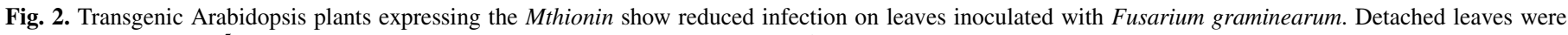

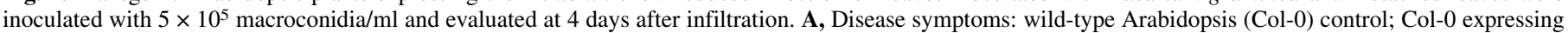

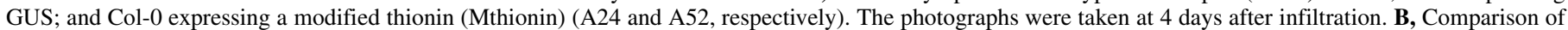

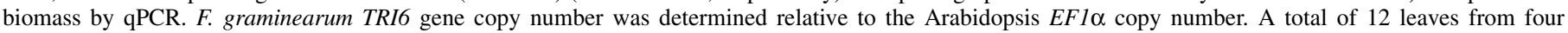

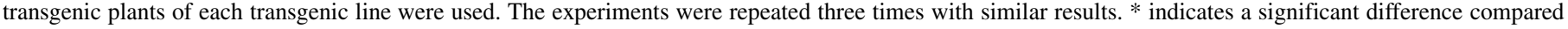
with the GUS transformant, by one-way analysis of variance and Tukey's post hoc test. 
A
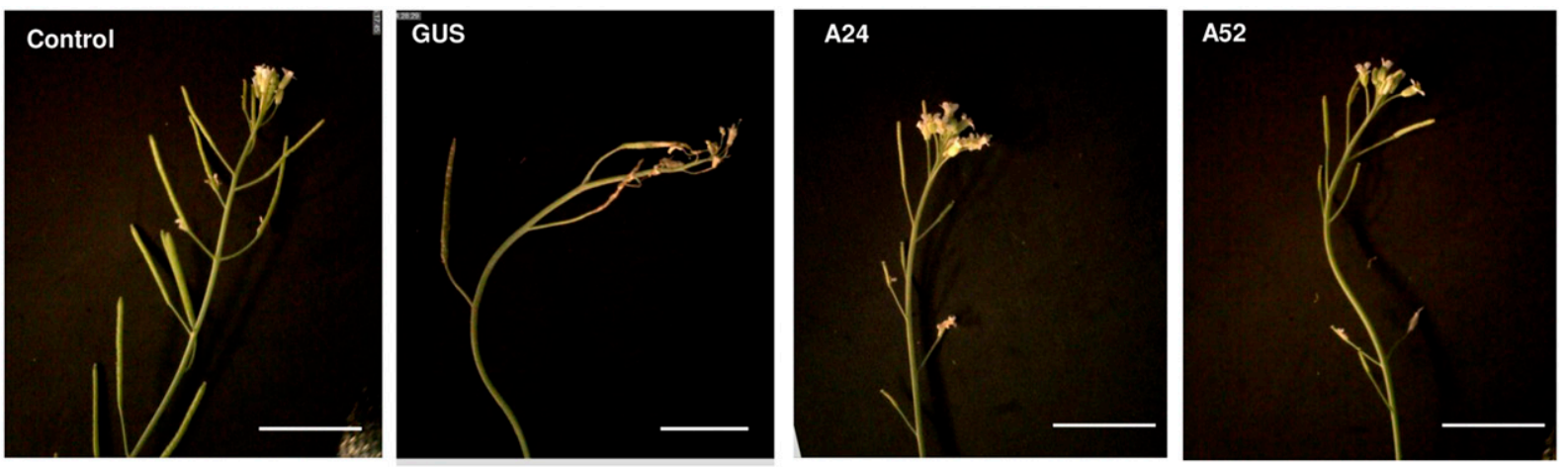

B

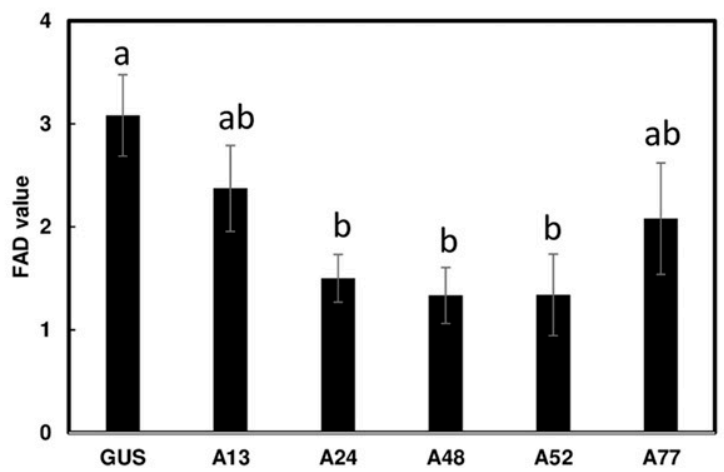

C

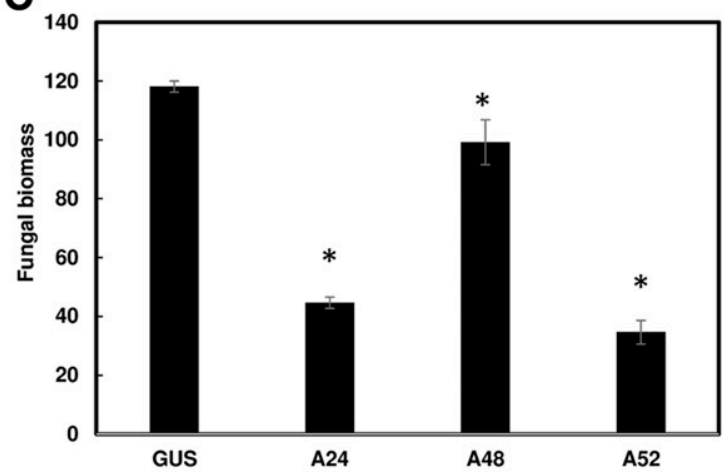

Fig. 3. Transgenic Arabidopsis expressing Mthionin show reduced disease. Plants including flowers were inoculated by spraying $5 \times 10^{5}$ macroconidia/ml. A, Disease symptoms. The photographs were taken at 8 days after inoculation. Control is a representative pathogen-free plant. Scale, $10 \mathrm{~mm}$. B, Disease evaluation by a numerical FAD score. A mixed model single factor analysis of variance (ANOVA) was performed for statistical analysis. Different letters indicate significant difference. C, Fungal biomass was determined by qPCR. Fusarium graminearum TRI6 gene copy number was expressed relative to the Arabidopsis EF1 $\alpha$ copy number. Eight transgenic plants from each transgenic line (GUS, Mthionin A24, Mthionin A48, or Mthionin A52) were inoculated and analyzed. * indicates a significant difference compared with the GUS control, by one-way ANOVA and Tukey's post hoc test.

A

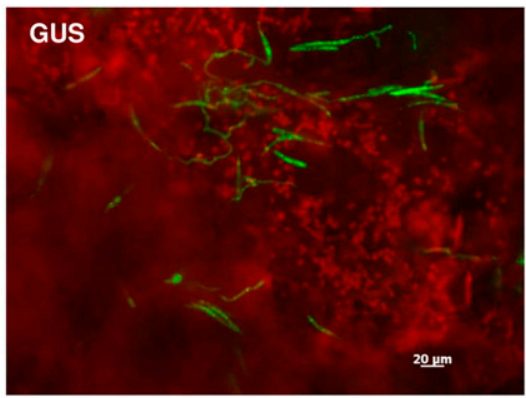

A24

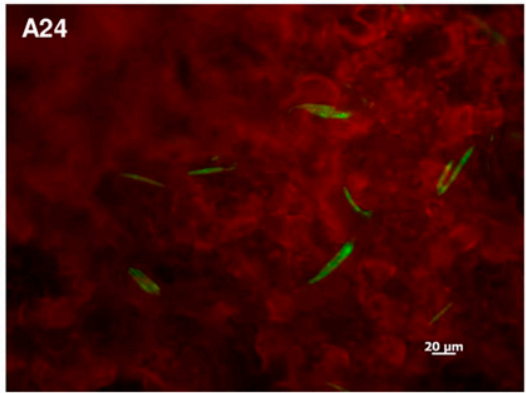

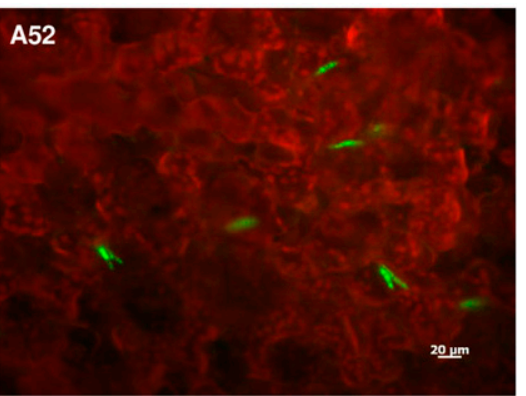

B

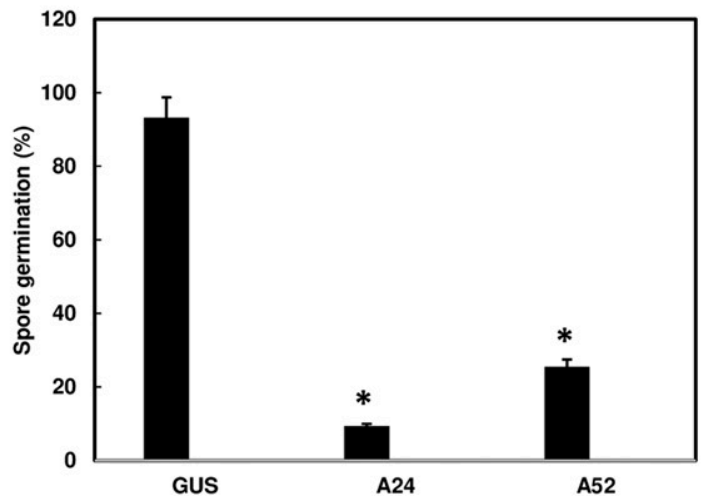

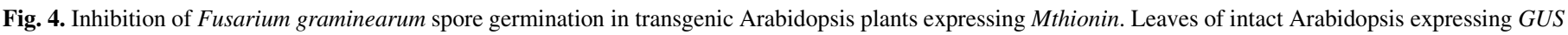
or Mthionin were infiltrated with an F. graminearum strain expressing green fluorescent protein (GFP). A, Representative fields of view from infiltrated zones. The

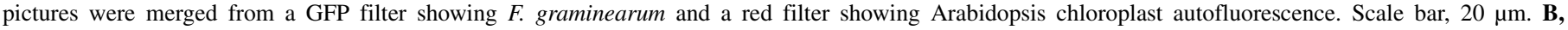

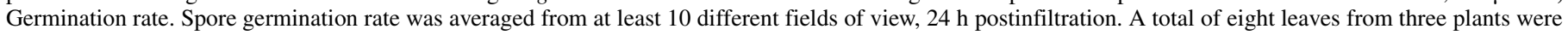

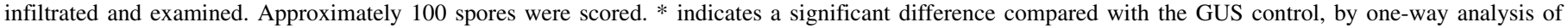
variance and Tukey's post hoc test. Experiments were repeated at least three times with similar results. 
GUS. Amplicon sequencing of bacterial marker genes captured approximately 1,000 different marker gene sequence variants and yielded a range of 1,924 to 33,105 sequences observed per sample. Among leaf tissue samples, fungal ITS2 amplicon sequencing produced predominantly observations of off-target taxa (e.g., algae), perhaps due to low input DNA concentrations, and these samples are not discussed further. Among root tissue samples, we detected 191 unique fungal ITS2 sequence variants, and obtained a range of 734 to 13,229 observations per sample.

As anticipated, bacterial communities differed strongly in association with Arabidopsis leaves versus roots (Fig. 7A). The relative abundances of many individual bacterial taxa (281 of the observed sequence variants) differed significantly between roots and leaves (Supplementary Figs. S2 and S3). Attempts to profile

\section{A}
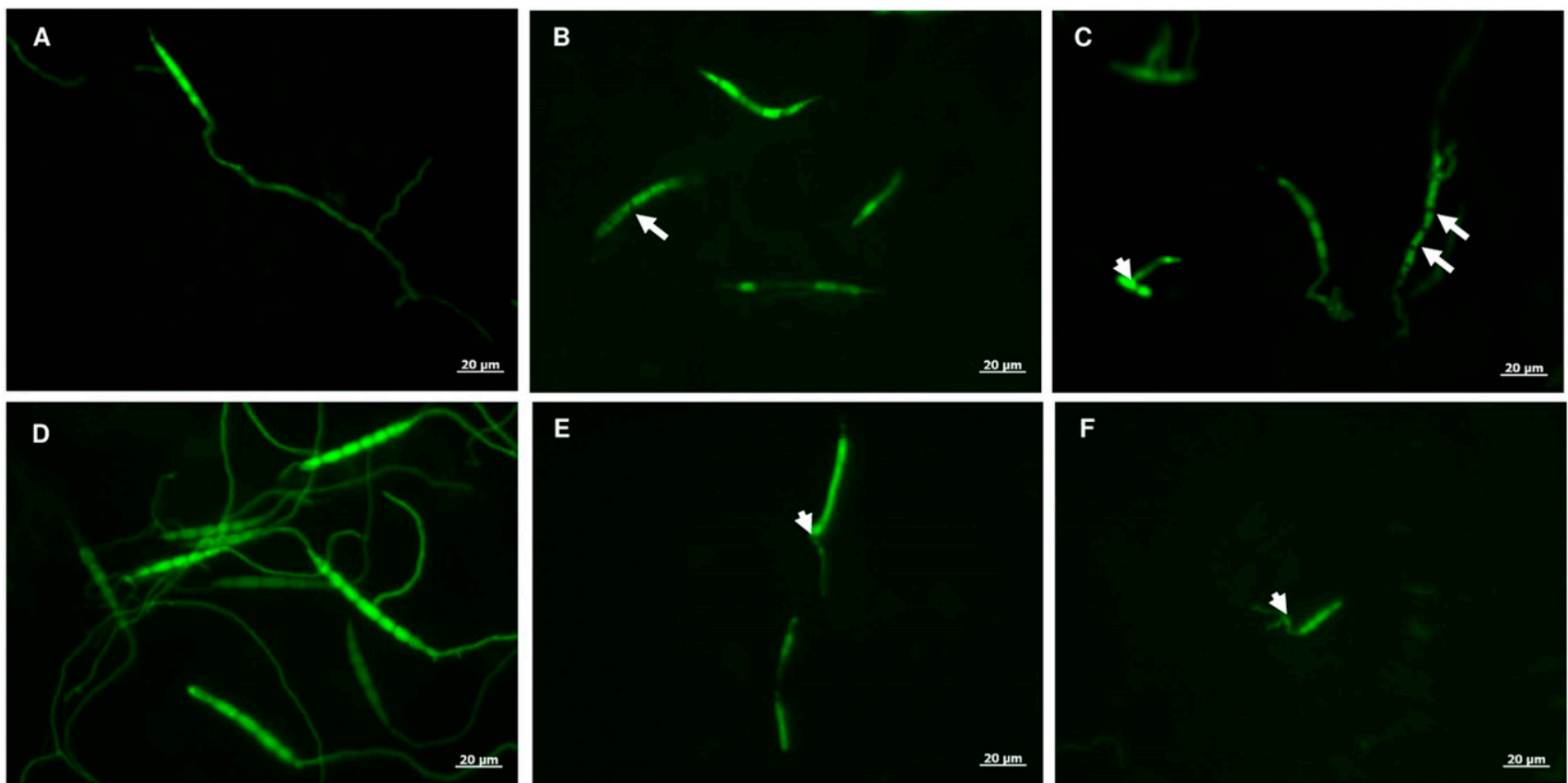

B

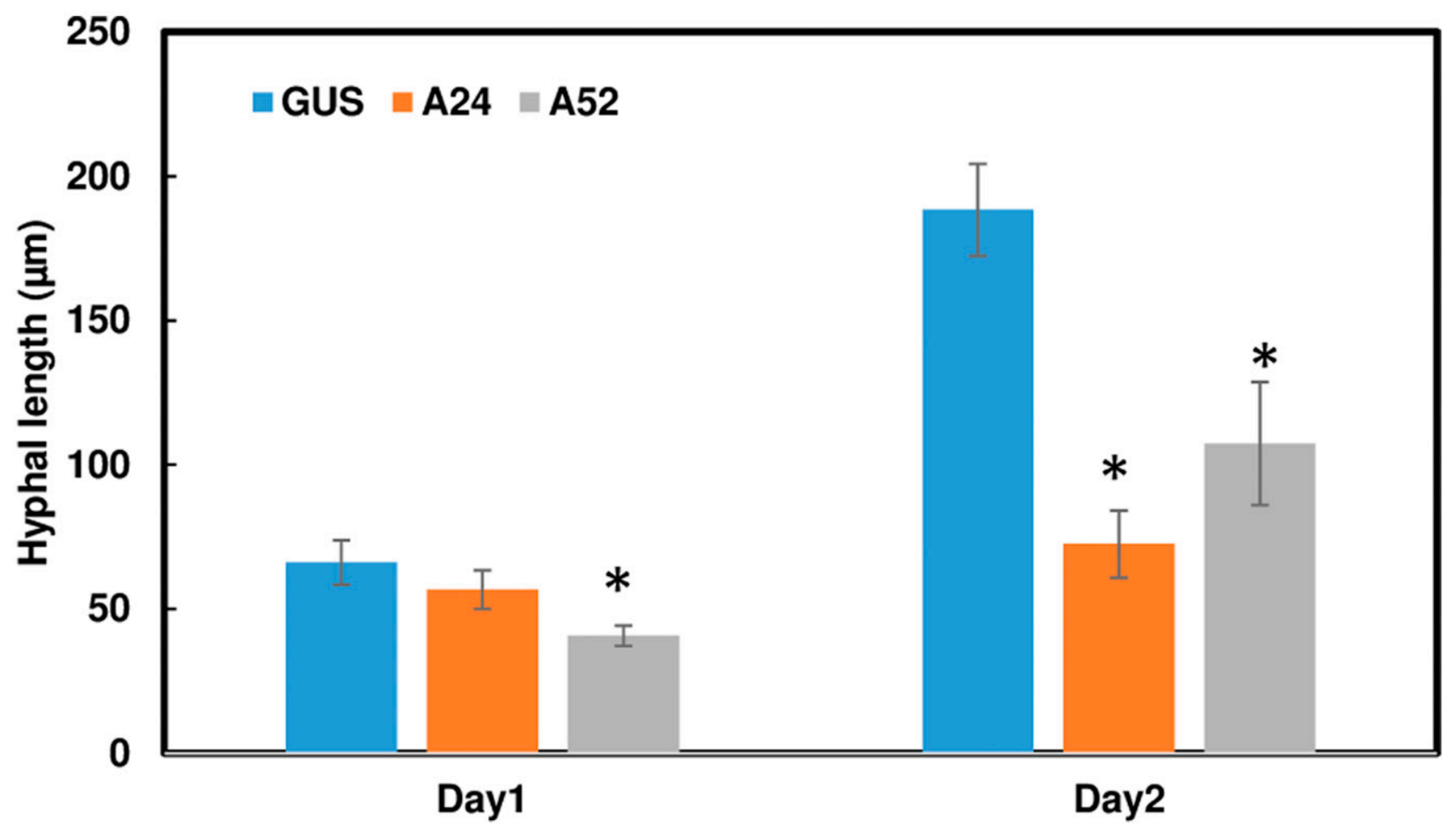

Fig. 5. Abnormal hyphal growth of Fusarium graminearum on Mthionin-expressing leaves. A, Germinated conidia were viewed at 24 and 48 h postinfiltration (hpi). Healthy hyphae were observed on GUS transgenic leaves at 24 hpi (A) and 48 hpi (D). Short, vacuolated abnormal hyphae were observed on Mthionin transgenic leaves (A24 and A52) at $24 \mathrm{hpi} \mathrm{(B} \mathrm{and} \mathrm{E),} \mathrm{and} 48 \mathrm{hpi} \mathrm{(C} \mathrm{and} \mathrm{F).} \mathrm{Arrows} \mathrm{indicate} \mathrm{enlarge} \mathrm{vacuoles,} \mathrm{and} \mathrm{arrowheads} \mathrm{indicate} \mathrm{curved} \mathrm{germ} \mathrm{tubes.} \mathrm{Scale,}$ $20 \mu \mathrm{m}$. B, Comparison of hyphal length at 24 and 48 hpi. The length of hyphae was measured using Image $\mathbf{J}$ software. * indicates a significant difference compared with the GUS control, by one-way analysis of variance and Tukey's post hoc test. Experiments were repeated at least twice with similar results. 
fungal communities associated with Arabidopsis leaves yielded primarily off-target ITS2 sequences (data not shown).

Against this background of broad-scale community change among plant tissues, impacts of plant genotype were very modest. Nevertheless, among bacteria, 12 sequence variants were more abundant in association with GUS transformants than with Mthionin A24 transformants, while eight sequence variants were more abundant in association with Mthionin A24 transformants than with GUS transformants (Fig. 8A). Similarly, 12 bacterial sequence variants were more abundant in association with GUS transformants than Mthionin A52 transformants, while four bacterial sequence variants were more abundant in association with Mthionin A52 transformants than GUS transformants (Fig. 8B). However, a similar number of sequence variants were found to differ in abundance between A24 versus A52 transformants (Fig. 8C).

Arabidopsis lines transformed with GUS or with Mthionin harbored very similar fungal communities in association with roots (Fig. 7B and Supplementary Fig. S4). However, several individual fungal taxa were found to be differentially abundant in association with roots of GUS transformants compared with root of Mthionin transformants A24 and A52. Specifically, one fungal ITS2 sequence variant from Fusarium was more abundant in association with GUS plants than with Mthionin A24 plants, while six fungal sequence variants were less abundant in association with GUS plants than with Mthionin A24 plants (Fig. 9A). Three fungal sequence variants were less abundant in association with GUS plants than with A52 plants (Fig. 9B). Again, a similar number of sequence variants were found to differ in abundance between A24 versus A52 transformants (Fig. 9C).

Tissue type (leaves versus roots) was a significant factor in explaining various measures of bacterial diversity (ANOVA; $P<$ 0.01) (Supplementary Fig. S5). However, plant genotype had no significant impact on either bacterial or fungal diversity (ANOVA; $P>0.1$, Supplementary Figs. S6 and S7).

\section{DISCUSSION}

We showed that expression of Mthionin in transgenic Arabidopsis plants enhanced resistance toward $F$. graminearum. We determined that the disease reduction in Mthionin transgenic Arabidopsis may be due to inhibition of $F$. graminearum spore germination and hyphal growth. In addition, we determined that plant defense genes involved in phytohormone signaling contribute to resistance toward F. graminearum in transgenic plants expressing Mthionin after $F$. graminearum inoculation. At the same time, microbiomes associated with these plants were similar in transgenic plants expressing Mthionin or GUS. Our results suggest that overexpression
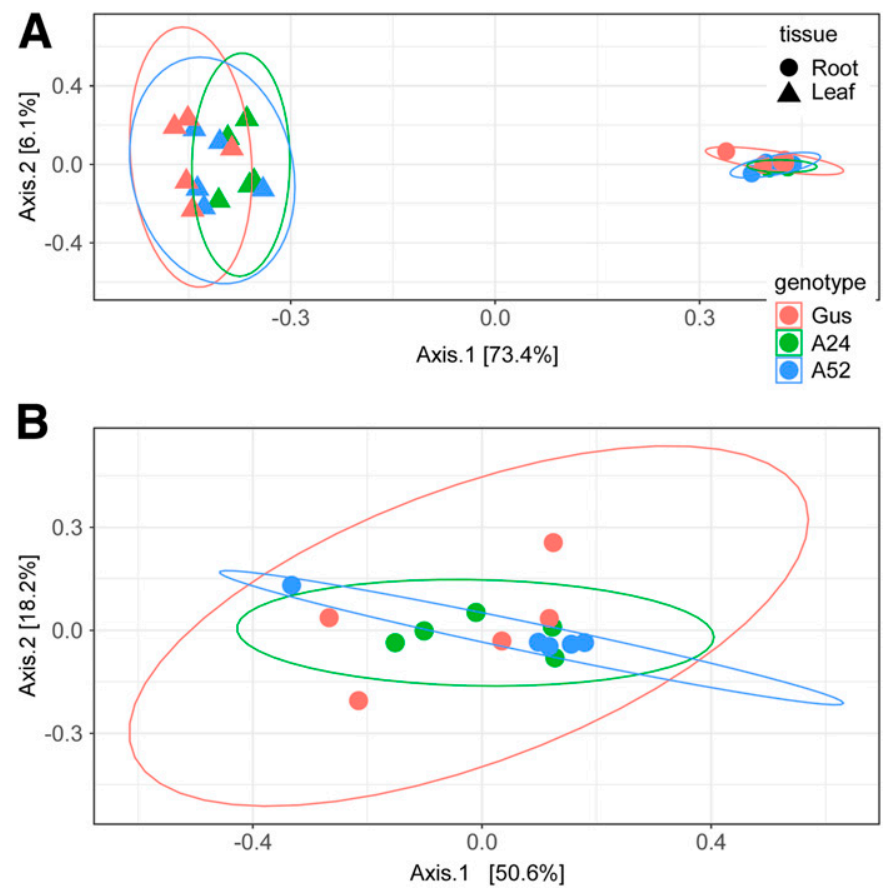

Fig. 7. Principal coordinate ordinations on $\mathbf{A}$, bacterial or $\mathbf{B}$, fungal community profiles. Input data are pairwise dissimilarities among samples, using the Bray-Curtis index. Samples originated from five transgenic plants of each line (GUS, Mthionin A24, or Mthionin A52).
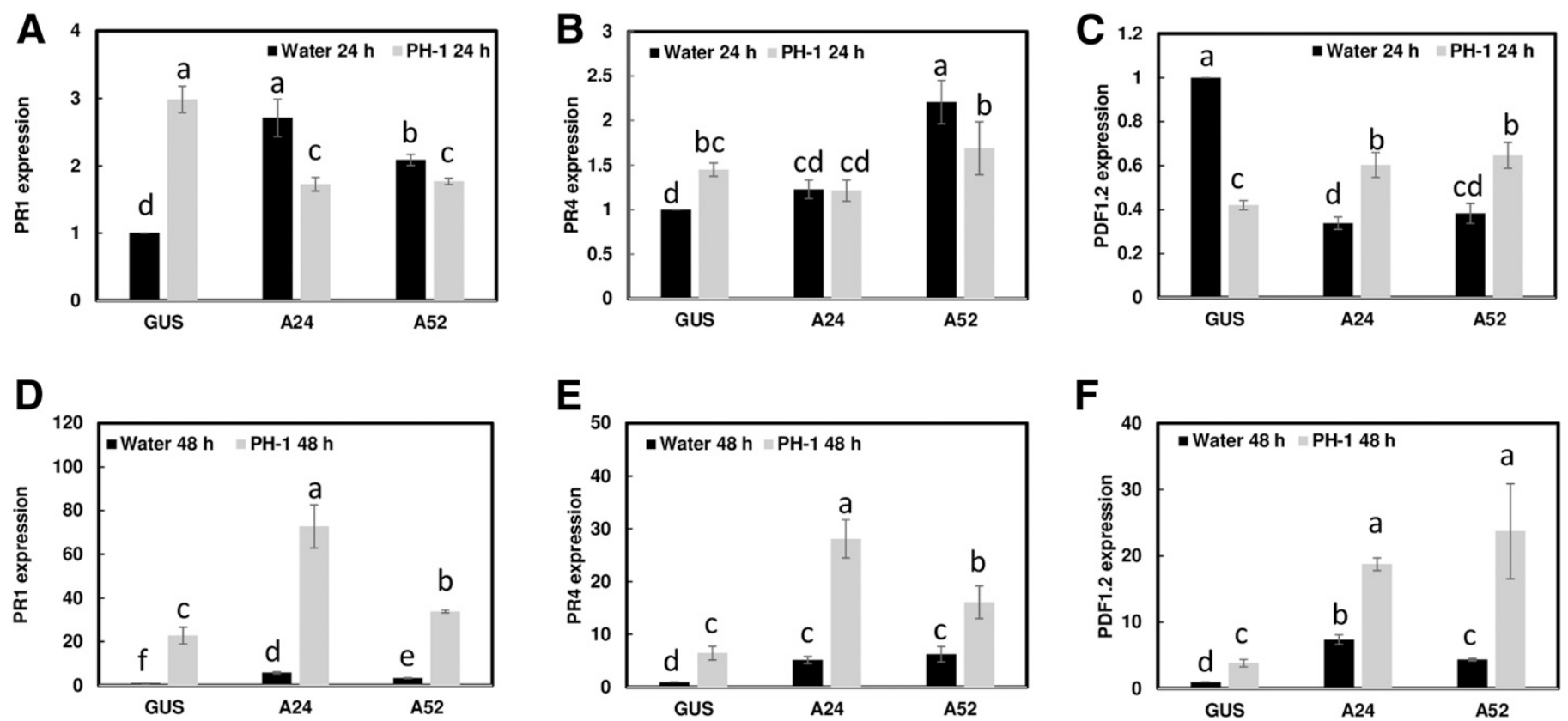

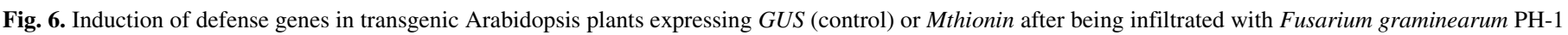

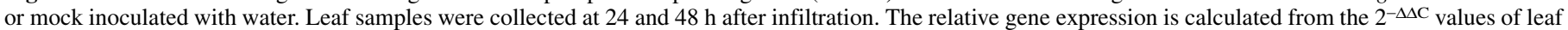

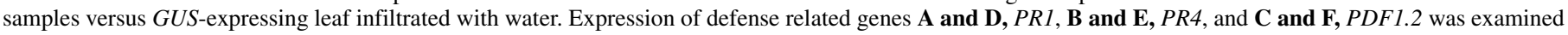

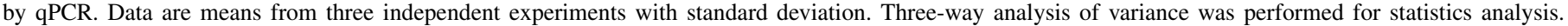
Different letters indicate statistically significant differences. 
of Mthionin in transgenic plants can provide resistance to fungal disease without substantial effect on broader microbial populations.

Transgenic Arabidopsis plants expressing Mthionin exhibited less fungal growth and produced more healthy siliques. The Mthionin transgenic plants displayed significantly less fungal biomass in infiltrated leaves or sprayed flowers with $F$. graminearum. This suggests Mthionin is effective against $F$. graminearum via inhibition of fungal spore germination and hyphal growth and enhanced plant defense responses (Figs. 4, 5, and 6). Overexpression of the thionin Thi2.4 in Arabidopsis inhibited F. graminearum by interaction with fungal fruit body lectin (Asano et al. 2013). Prior studies also demonstrated that thionin production increased resistance to a variety of plant diseases. For example, the expression of a thionin protein in transgenic rice resulted in its accumulation in cell walls and stopped the invasion of Burkholderia plantarii at the surface of stomata (Iwai et al. 2002). Transgenic citrus expressing Mthionin showed reduced canker lesions and $X$. citri growth. Additionally, a significantly lower ' $\mathrm{Ca}$. Liberibacter asiaticus' titer was observed in Mthionin transgenic citrus compared with controls (Hao et al. 2016a). Most thionins are toxic to microbes by disrupting cell membrane function (Bohlmann et al. 1988). Regarding of the potential toxicity of Mthionin in transgenic plants, we made efforts to reduce natural thionin toxicity by amino acid substitution and addition of additional amino acids at C-terminus (Hao et al. 2016a). It has been demonstrated that the substitution of Arg with Phe at the Cterminus can reduce thionin toxicity (Pelegrini and Franco 2005). It

\section{A}
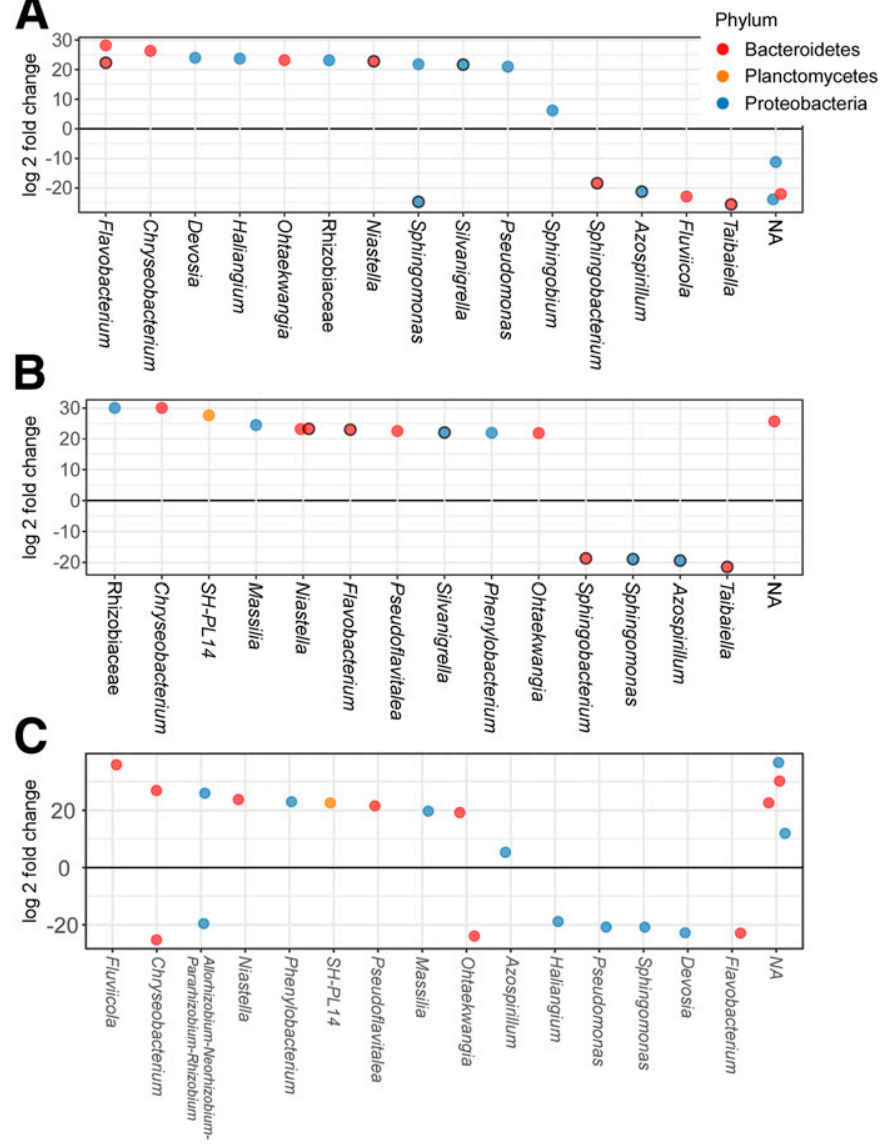

Fig. 8. Summary of bacterial taxa that differed significantly in abundance among Arabidopsis transformants. A, GUS versus A24; B, GUS versus A52; and $\mathbf{C}$, A24 versus A52. Normalized taxon counts were modeled as responsive to plant tissue + genotype. Positive fold change values indicate greater abundance in association with GUS transformants (A and B) or with A24 (C), with the opposite for negative fold change values. Points outlined in black represent taxa that responded consistently and significantly to both transformed plant lines. NA indicates sequence variants that could not be confidently classified to the rank of genus. Data analysis were performed with five biological replicates. will be necessary to determine potential Mthionin toxicity in transgenic grain or fruit. Alternatively, tissue specific or pathogen induced gene promoters will be a better choice to drive Mthionin expressing in transgenic plants.

Gene expression study revealed varying levels of Mthionin expression in the different Arabidopsis transgenic plants. Gene expression was higher in the transgenic plants Mthionin-A24 and A52 compared with transgenic lines A5 (Fig. 1). Gene expression level can be affected by the location of gene insert and gene silence, which can be induced by homologs when foreign genes are highly expressed (Rajeevkumar et al. 2015). Studies showed some degree of correlation between the level of transgene expression and disease resistance (Lu et al. 2013). Our results showed that high transgene expression in Mthionin A24 and A52 provided effective inhibition of fungal growth in Arabidopsis floral and leaf tissue (Figs. 2 and 3). However, fungal growth inhibition is not consistent in transgenic line A48 that had medium level gene expression. A better correlation has been shown between the levels of lactoferrin protein expression in transgenic wheat lines and the level of resistance against F. graminearum (Han et al. 2012). We speculate that Mthionin peptide levels will be correlated with the ability of fungal inhibition. Further investigations are needed to produce Mthionin monoclonal antibodies and use Western blots to quantify levels of the Mthionin peptide.

In general, SA pathway activates resistance to biotrophic pathogens, whereas JA/ET pathways mediate resistance to necrotrophic pathogens as well as to herbivorous pests (Glazebrook 2005). $F$. graminearum is considered as a hemibiotrophic pathogens, both SA and JA/ET pathways are involved in FHB resistance during

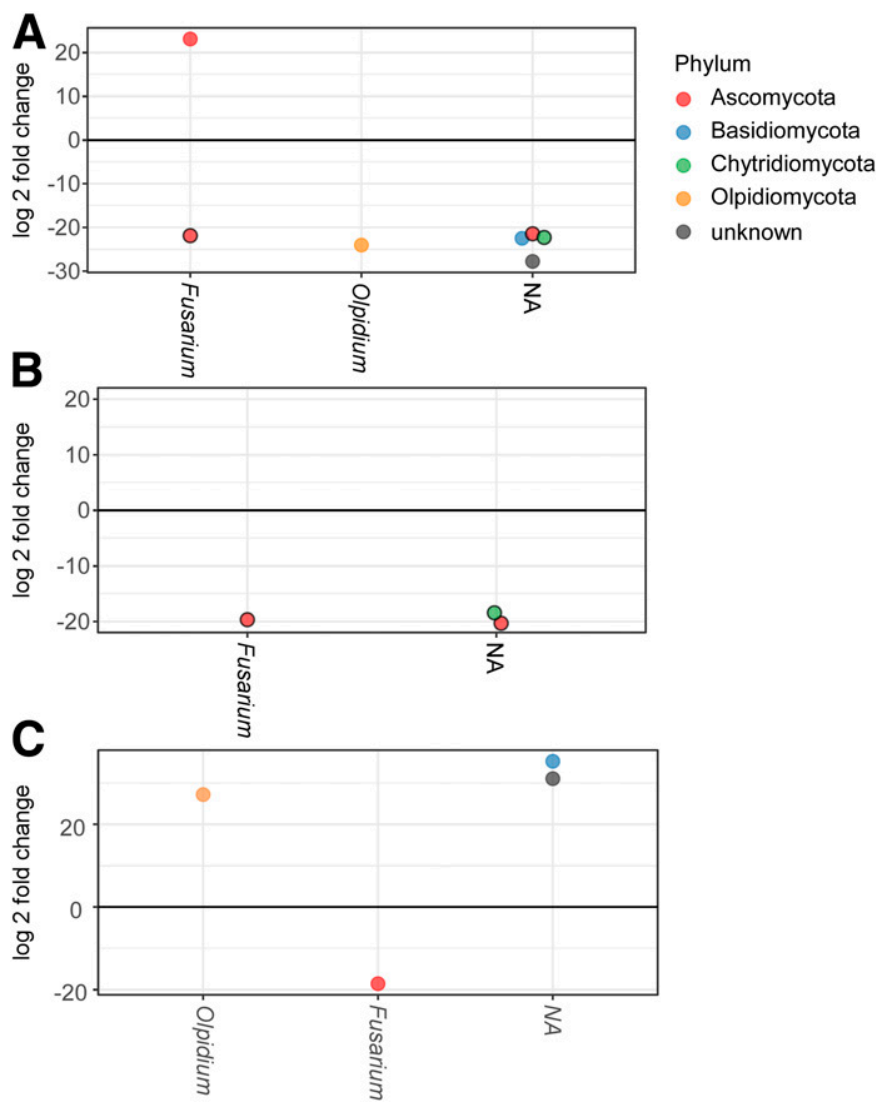

Fig. 9. Summary of fungal taxa that differed significantly in abundance among Arabidopsis transformants. A, GUS versus A24; B, GUS versus A52; and C, A24 versus A52. Normalized taxon counts were modeled as responsive to plant genotype. Positive fold change values indicate greater abundance in association with GUS transformants (A and B) or with A24 (C), with the opposite for negative fold change values. Points outlined in black represent taxa that responded consistently and significantly to both transformed plant lines. NA indicates sequence variants that could not be confidently classified to the rank of genus. Data analysis were performed with five replicates. 
F. graminearum infection of Arabidopsis and wheat (Brewer and Hammond-Kosack 2015). Mthionin transgenic Arabidopsis displayed significant induction of SA, JA/ET marker genes compared with GUS plants at $48 \mathrm{hpi}$ after $F$. graminearum inoculation. This finding suggests that Mthionin, as a plant defense peptide, may elevate plant phytohormone signaling pathways against $F$. graminearum. A previous study showed that transgenic Arabidopsis overexpressing an endogenous peptide AtPep1 precursor induced expression of PDF1.2 (Huffaker et al. 2006). It is worth noting that the induction of defense marker genes was also observed in GUS transgenic Arabidopsis after F. graminearum inoculation compared with mock control (Fig. 6). Similarly, expression of the $P R 1$ and $P D F 1.2$ genes in Arabidopsis has been shown after $F$. graminearum inoculation (Nishiuchi et al. 2006). These results agree with previous studies and show that both SA and JA/ET pathway are involved during $F$. graminearum and plant interactions. Our results also indicate that Mthionin may boost plant defense responses via uplifting of plant hormone signaling. Further investigations are needed to determine how Mthionin interacts with these defense pathways. It will be interesting to determine whether phytohormone-signaling pathways play a similar role in Mthionin transgenic plants against other diseases.

Most plant thionins display antibacterial or antifungal activity, although only a few showed activities against both bacterial and fungal pathogens (Sathoff and Samac 2019). For example, Pth-St1, a thionin from potato (Solanum tuberosum) tubers, displayed broadspectrum activity against fungi and bacteria (Moreno et al. 1994). MtDef5, isolated from the model legume Medicago truncatula, displayed both antibacterial and antifungal activity (Islam et al. 2017; Velivelli et al. 2018). In addition to a prior report on enhanced resistance against several bacterial diseases (Hao et al. 2016a), this study showed that transgenic Arabidopsis expressing Mthionin increased resistance toward fungal pathogen $F$. graminearum. Taken together, these results indicate that Mthionin has antifungal and antibacterial activity.

Since the Mthionin showed activity against bacterial and fungal pathogens, we investigated the overall microbial populations associated with Mthionin-expressing plants. Studies have demonstrated that the GUS gene driven by a $35 \mathrm{~S}$ promoter was expressed at a similar level in leaves and roots of transgenic citrus (Dutt et al. 2016). Mthionin expression had only modest impacts on overall bacterial and fungal communities in leaves and roots. This result is consistent with studies showing that transgenic plants overexpressing a T4-lysoenzyme, Bacillus thuringiensis (Bt) genes or plant transcription factors did not significantly affect the diversity and population of microbial communities in transgenic potato, maize, and poplar (Heuer and Smalla 1999; Silva et al. 2014; Wang et al. 2019). However, in our study, several individual taxa were found to differ significantly in relative abundance among transformants expressing $G U S$ versus Mthionin. In many cases, these taxa were not found consistently even in the treatment for which their abundance was elevated. For instance, a fungal ITS2 sequence variant belonging to Fusarium was found to be more abundant in association with roots of Mthionin-producing A52 transformants compared with roots of GUS transformants (Fig. 8B). However, this sequence variant was only observed in one in five A52 transformant root samples compared with zero in five GUS transformant root samples. Furthermore, it is worth highlighting that microbiome rearrangements in GUS versus Mthionin transformants were equivalent in magnitude to the contrast between two different Mthionin transformants (i.e., A24 versus A52). This suggests that the observed changes in the relative abundance of a small number of taxa are in line with what would be expected due to minor environmental or technical variation.

While there may seem to be a contradiction in finding effective control of pathogens without corresponding effects on the wider microbiome, this difference may be attributed to the intimacy of interaction. For instance, we directly infiltrated $F$. graminearum spores into leaves, while most of the bacteria we observed by microbiome profiling may have been epiphytic and thus less exposed to the Mthionin (although leaves were wiped briefly, we certainly did not remove all surface bacteria). Our microbiome profiles may also have detected nonviable organisms (including some that may have been killed by Mthionin) whose DNA remained available for amplification. In addition, the effect of Mthionin on transgenic plants may be too subtle to be detected in a short period, because the plants were exposed to microbial populations from field soil for only 1 month. It would be valuable to assess the impacts of Mthionin expression on plant-associated microbiomes under more realistic field conditions, as the use of potting soil and incubator conditions likely impacted microbiome dynamics. For instance, our ITS2 amplicon sequence data suggest that there were very few fungi associated with Arabidopsis leaves in our experiment, which is unlikely to be the case under field conditions.

Conclusions. In summary, expression of Mthionin provides resistance toward the fungal pathogen $F$. graminearum. We demonstrate that transgenic Arabidopsis plants expressing Mthionin showed reduced fungal development by inhibiting fungal spore germination and hyphal growth. Our data demonstrated that Mthionin may enhance SA/JA-mediated defense against $F$. graminearum infection. The Mthionin transgenic crops may provide broad-spectrum disease resistance and ultimately reduce associated mycotoxin contamination. There does not appear to be cause for concern about the effects of Mthionin expression on the wider plant-associated microbiome.

\section{ACKNOWLEDGMENTS}

We thank Thomas Usgaard, Ellie Tiley, Jake Brown, and Amy McGovern for their excellent technical help. We thank Deb Palmquist for assisting in statistical analysis. We also thank Robert Proctor for providing a F. graminearum green fluorescent protein strain.

\section{LITERATURE CITED}

Ali, S., Ganai, B. A., Kamili, A. N., Bhat, A. A., Mir, Z. A., and Bhat, J. A. 2018. Pathogenesis-related proteins and peptides as promising tools for engineering plants with multiple stress tolerance. Microbiol. Res. 212-213:29-37.

Asano, T., Miwa, A., Maeda, K., Kimura, M., and Nishiuchi, T. 2013. The secreted antifungal protein thionin 2.4 in Arabidopsis thaliana suppresses the toxicity of a fungal fruit body lectin from Fusarium graminearum. PLoS Pathog 9:e1003581.

Bakker, M. G. 2018. A fungal mock community control for amplicon sequencing experiments. Mol. Ecol. Resour. 18:541-556.

Bengtsson-Palme, J., Ryberg, M., Hartmann, M., Branco, S., Wang, Z., Godhe, A., De Wit, P., Sanchez-Garcia, M., Ebersberger, I., Sousa, F., Amend, A., Jumpponen, A., Unterseher, M., Kristiansson, E., Abarenkov, K., Yann, B., Sanli, K., Eriksson, K., Vik, U., and Nilsson, R. H. 2013. Improved software detection and extraction of ITS1 and ITS2 from ribosomal ITS sequences of fungi and other eukaryotes for analysis of environmental sequencing data. Methods Ecol. Evol. 4:914-919.

Bohlmann, H., Clausen, S., Behnke, S., Giese, H., Hiller, C., Reimann-Philipp, U., Schrader, G., Barkholt, V., and Apel, K. 1988. Leaf-specific thionins of barley-A novel class of cell wall proteins toxic to plant-pathogenic fungi and possibly involved in the defense mechanism of plants. EMBO J. 7: 1559-1565.

Brewer, H. C., and Hammond-Kosack, K. E. 2015. Host to a stranger: Arabidopsis and Fusarium ear blight. Trends Plant Sci. 20:651-663.

Callahan, B., Sankaran, K., Fukuyama, J., McMurdie, P., and Holmes, S. 2016a. Bioconductor workflow for microbiome data analysis: From raw reads to community analyses. F1000 Res. 5:1492.

Callahan, B. J., McMurdie, P. J., Rosen, M. J., Han, A. W., Johnson, A. J. A., and Holmes, S. P. 2016b. DADA2: High-resolution sample inference from Illumina amplicon data. Nat. Methods 13:581-583.

Caporaso, J. G., Lauber, C. L., Walters, W. A., Berg-Lyons, D., Lozupone, C. A., Turnbaugh, P. J., Fierer, N., and Knight, R. 2011. Global patterns of $16 \mathrm{~S}$ rRNA diversity at a depth of millions of sequences per sample. Proc. Natl. Acad. Sci. USA 108:4516-4522.

Castro, M. S., and Fontes, W. 2005. Plant defense and antimicrobial peptides. Protein Pept. Lett. 12:11-18.

Chan, Y. L., and Prasad, V., Sanjaya, Chen, K. H., Liu, P. C., Chan, M. T., and Cheng, C. P. 2005. Transgenic tomato plants expressing an Arabidopsis thionin (Thi2.1) driven by fruit-inactive promoter battle against phytopathogenic attack. Planta 221:386-393. 
Chen, X., Steed, A., Harden, C., and Nicholson, P. 2006. Characterization of Arabidopsis thaliana-Fusarium graminearum interactions and identification of variation in resistance among ecotypes. Mol. Plant Pathol. 7:391-403.

Cuzick, A., Urban, M., and Hammond-Kosack, K. 2008. Fusarium graminearum gene deletion mutants map1 and tri5 reveal similarities and differences in the pathogenicity requirements to cause disease on Arabidopsis and wheat floral tissue. New Phytol. 177:990-1000.

Dutt, M. L., Erpen, L., Ananthakrishnan, G., Barthe, G. A., Brlansky, R. H., Maiti, I. B., and Grosser, J. W. 2016. Comparative expression analysis of five caulimovirus promoters in citrus. Plant Cell Organ Tissue Cult. 126:229-238.

Edgar, R. C., and Flyvbjerg, H. 2015. Error filtering, pair assembly and error correction for next-generation sequencing reads. Bioinformatics 31:3476-3482.

Epple, P., Apel, K., and Bohlmann, H. 1995. An Arabidopsis thaliana thionin gene is inducible via a signal transduction pathway different from that for pathogenesis-related proteins. Plant Physiol. 109:813-820.

Epple, P., Apel, K., and Bohlmann, H. 1997. Overexpression of an endogenous thionin enhances resistance of Arabidopsis against Fusarium oxysporum. Plant Cell 9:509-520.

Garcia, I., Rodgers, M., Pepin, R., Hsieh, T. F., and Matringe, M. 1999. Characterization and subcellular compartmentation of recombinant 4hydroxyphenylpyruvate dioxygenase from Arabidopsis in transgenic tobacco. Plant Physiol. 119:1507-1516.

Glazebrook, J. 2005. Contrasting mechanisms of defense against biotrophic and necrotrophic pathogens. Annu. Rev. Phytopathol. 43:205-227.

Guzmán-Rodríguez, J. J., Ochoa-Zarzosa, A., López-Gómez, R., and López-Meza, J. E. 2015. Plant antimicrobial peptides as potential anticancer agents. BioMed. Res. Int. 2015:735087.

Han, J., Lakshman, D. K., Galvez, L. C., Mitra, S., Baenziger, P. S., and Mitra, A. 2012. Transgenic expression of lactoferrin imparts enhanced resistance to head blight of wheat caused by Fusarium graminearum. BMC Plant Biol. 12:33.

Hao, G., McCormick, S., Vaughan, M. M., Naumann, T., Kim, H.-S., Proctor, R. H., Kelly, A., and Ward, T. 2019. Fusarium graminearum arabinanase (Arb93B) enhances wheat head blight susceptibility by suppressing plant immunity. Mol. Plant-Microbe Interact. 32:888-898.

Hao, G., Pitino, M., Duan, Y., and Stover, E. 2016b. Reduced susceptibility to Xanthomonas citri in transgenic citrus expressing the FLS2 receptor from Nicotiana benthamiana. Mol. Plant-Microbe Interact. 29:132-142.

Hao, G., Stover, E., and Gupta, G. 2016a. Overexpression of a modified plant thionin enhances disease resistance to citrus canker and huanglongbing (HLB). Front. Plant Sci. 7:1078.

Heuer, H., and Smalla, K. 1999. Bacterial phyllosphere communities of Solanum tuberosum L. and T4-lysozyme-producing transgenic variants. FEMS Microbiol. Ecol. 28:357-371.

Huffaker, A., Pearce, G., and Ryan, C. A. 2006. An endogenous peptide signal in Arabidopsis activates components of the innate immune response. Proc. Natl. Acad. Sci. USA 103:10098-10103.

Islam, K. T., Velivelli, S. L. S., Berg, R. H., Oakley, B., and Shah, D. M. 2017. A novel bi-domain plant defensin MtDef5 with potent broad-spectrum antifungal activity binds to multiple phospholipids and forms oligomers. Sci. Rep. 7:1-13.

Iwai, T., Kaku, H., Honkura, R., Nakamura, S., Ochiai, H., Sasaki, T., and Ohashi, Y. 2002. Enhanced resistance to seed-transmitted bacterial diseases in transgenic rice plants overproducing an oat cell-wall-bound thionin. Mol. Plant-Microbe Interact. 15:515-521.

Jung, Y. J., and Kang, K. K. 2014. Application of antimicrobial peptides for disease control in plants. Plant Breed. Biotechnol. 2:1-13.

Kang, Z., and Buchenauer, H. 2003. Immunocytochemical localization of cell wall-bound thionins and hydroxyproline-rich glycoproteins in Fusarium culmorum-infected wheat spikes. J. Phytopathol. 151:120-129.

Kõljalg, U., Nilsson, R. H., Abarenkov, K., Tedersoo, L., Taylor, A. F., Bahram, M., Bates, S. T., Bruns, T. D., Bengtsson-Palme, J., Callaghan, T. M., Douglas, B., Drenkhan, T., Eberhardt, U., Dueñas, M., Grebenc, T., Griffith, G. W., Hartmann, M., Kirk, P. M., Kohout, P., Larsson, E., Lindahl, B. D., Lücking, R., Martín, M. P., Matheny, P. B., Nguyen, N. H., Niskanen, T., Oja, J., Peay, K. G., Peintner, U., Peterson, M., Põldmaa, K., Saag, L., Saar, I., Schüßler, A., Scott, J. A., Senés, C., Smith, M. E., Suija, A., Taylor, D. L., Telleria, M. T., Weiss, M., and Larsson, K. 2013. Towards a unified paradigm for sequence-based identification of fungi. Mol. Ecol. 22:5271-5277.

Lacerda, A. F. L., Vasconcelos, E. A. R., Pelegrini, P. B., and Grossi de Sa, M. F. 2014. Antifungal defensins and their role in plant defense. Front. Microbiol. 5:116.

Livak, K. J., and Schmittgen, T. D. 2001. Analysis of relative gene expression data using real-time quantitative PCR and the 2(-Delta $\mathrm{C}(\mathrm{T})$ ) method. Methods 25:402-408.

Love, M. I., Huber, W., and Anders, S. 2014. Moderated estimation of fold change and dispersion for RNA-seq data with DESeq2. Genome Biol. 15:550.
Lu, H., Zhang, C., Albrecht, U., Shimizu, R., Wang, G., and Bowman, K. D. 2013. Overexpression of a citrus NDR1 ortholog increases disease resistance in Arabidopsis. Front. Plant Sci. 4:157.

Makandar, R., Essig, J. S., Schapaugh, M. A., Trick, H. N., and Shah, J. 2006. Genetically engineered resistance to Fusarium head blight in wheat by expression of Arabidopsis NPR1. Mol. Plant-Microbe Interact. 19:123-129.

Martin, M. 2011. Cutadapt removes adapter sequences from high-throughput sequencing reads. EMBnet J. 17:10-12.

McMurdie, P. J., and Holmes, S. 2013. phyloseq: An R package for reproducible interactive analysis and graphics of microbiome census data. PLoS One 8:e61217.

Montesinos, E. 2007. Antimicrobial peptides and plant disease control. FEMS Microbiol. Lett. 270:1-11.

Moreno, M., Segura, A., and Garcia-Olmedo, F. 1994. Pseudothionin-St1, a potato peptide active against potato pathogens. Eur. J. Biochem. 223:135-139.

Muramoto, N., Tanaka, T., Shimamura, T., Mitsukawa, N., Hori, E., Koda, K., Otani, M., Hirai, M., Nakamura, K., and Imaeda, T. 2012. Transgenic sweet potato expressing thionin from barley gives resistance to black rot disease caused by Ceratocystis fimbriata in leaves and storage roots. Plant Cell Rep. 31:987-997.

Nalam, V. J., Alam, S., Keereetaweep, J., Venables, B., Burdan, D., Lee, H., Trick, H. N., Sarowar, S., Makandar, R., and Shah, J. 2015. Facilitation of Fusarium graminearum infection by 9-lipoxygenases in Arabidopsis and wheat. Mol. Plant-Microbe Interact. 28:1142-1152.

Nishiuchi, T., Masuda, D., Nakashita, H., Ichimura, K., Shinozaki, K., Yoshida, S., Kimura, M., Yamaguchi, I., and Yamaguchi, K. 2006. Fusarium phytotoxin trichothecenes have an elicitor-like activity in Arabidopsis thaliana, but the activity differed significantly among their molecular species. Mol. Plant-Microbe Interact. 19:512-520.

Oard, S. V. 2011. Deciphering a mechanism of membrane permeabilization by alpha-hordothionin peptide. Biochim. Biophys. Acta 1808:1737-1745.

Pelegrini, P. B., and Franco, O. L. 2005. Plant gamma-thionins: Novel insights on the mechanism of action of a multi-functional class of defense proteins. Int. J. Biochem. Cell 37:2239-2253.

Quast, C., Pruesse, E., Yilmaz, P., Gerken, J., Schweer, T., Yarza, P., Peplies, J., and Glöckner, F. O. 2013. The SILVA ribosomal RNA gene database project: Improved data processing and web-based tools. Nucleic Acids Res.: D590-D596.

Rajeevkumar, S., Anunanthini, P., and Sathishkumar, R. 2015. Epigenetic silencing in transgenic plants. Front Plant Sci. 6:693.

R Core Team. 2018. R: A language and environment for statistical computing. R Foundation for Statistical Computing, Vienna, Austria.

Sathoff, A. E., and Samac, D. A. 2019. Antibacterial activity of plant defensins. Mol. Plant-Microbe Interact. 32:507-514.

Schliep, K. P. 2011. phangorn: Phylogenetic analysis in R. Bioinformatics 27: 592-593.

Silva, D. A. D., Cotta, S. R., Vollú, R. E., Jurelevicius, D. A., Marques, J. M., Marriel, I. E., and Seldin, L. 2014. Endophytic microbial community in two transgenic maize genotypes and in their near-isogenic non-transgenic maize genotype. BMC Microbiol. 14:332.

Stover, E., Gupta, G., and Hao, G. 2017. Thionin-D4E1 chimeric protein protects plants against bacterial infections. U.S. Patent No. 9,725,734. U.S. Patent and Trademark Office, Washington, DC.

Thevissen, K., Ghazi, A., DeSamblanx, G. W., Brownlee, C., Osborn, R. W., and Broekaert, W. F. 1996. Fungal membrane responses induced by plant defensins and thionins. J. Biol. Chem. 271:15018-15025.

Toju, H., Tanabe, A. S., Yamamoto, S., and Sato, H. 2012. High-coverage ITS primers for the DNA-based identification of Ascomycetes and Basidiomycetes in environmental samples. PLoS One 7:e40863.

Urban, M., Daniels, S., Mott, E., and Hammond-Kosack, K. 2002. Arabidopsis is susceptible to the cereal ear blight fungal pathogens Fusarium graminearum and Fusarium culmorum. Plant J. 32:961-973.

Velivelli, S. L. S., Islam, K. T., Hobson, E., and Shah, D. M. 2018. Modes of action of a bi-domain plant defensin MtDef5 against a bacterial pathogen Xanthomonas campestris. Front. Microbiol. 9:934.

Vernon, L. P. 1992. Pyrularia thionin: Physical properties, biological responses and comparison to other thionins and cardiotoxin. Toxin Rev. 11: 169-191

Wang, Q., Garrity, G. M., Tiedje, J. M., and Cole, J. R. 2007. Nä̈ve Bayesian classifier for rapid assignment of rRNA sequences into the new bacterial taxonomy. Appl. Environ. Microbiol. 73:5261-5267.

Wang, Y., Zhang, W., Ding, C., Zhang, B., Huang, Q., Huang, R., and Su, X. 2019. Endophytic communities of transgenic poplar were determined by the environment and niche rather than by transgenic events. Front. Microbiol. 10:588. 